\title{
Food Vending Among Men in Kumasi: Socio-Cultural Advantages, Constraints, and Coping Strategies
}

\author{
John Boulard Forkuor ${ }^{1}$, Kofi Osei Akuoko ${ }^{1}$, Eric Henry Yeboah, ${ }^{1}$ Thilde Rheinländer ${ }^{2} \&$ Helle Samuelsen ${ }^{2}$ \\ ${ }^{1}$ Department of Sociology and Social Work, Faculty of Social Sciences, Kwame Nkrumah University of Science and \\ Technology, Kumasi, Ghana \\ ${ }^{2}$ Department of International Health, Immunology and Microbiology, Faculty of Health Sciences University of \\ Copenhagen, CSS, Øster Farimagsgade 5, DK-1014 Copenhagen, Denmark \\ ${ }^{3}$ Faculty of Social Sciences, University of Copenhagen, Øster Farimagsgade 5, DK-1353 Copenhagen, Denmark \\ Correspondence: John Boulard Forkuor, Department of Sociology and Social Work, Faculty of Social Sciences, Kwame \\ Nkrumah University of Science and Technology, Kumasi, Ghana.
}

Received: January 5, 2016

doi:10.11114/ijsss.v4i2.1278
Accepted: January 19, 2016

Available online: January 27, 2016

\begin{abstract}
Research on men in female-dominated occupations has focused mainly on formal sector occupations in North American and Western European settings. It remains unclear whether men in informal sector occupations in the Global South enjoy advantages, face challenges and adopt coping strategies that are similar to those documented in literature. This research focuses on men in an informal and female-dominated occupation in Ghana. Using semi-structured interviews, this research explores the advantages men enjoy as traditional food vendors, their constraints, and the coping strategies they adopt. This research found that while male traditional food vendors face some social ridicule, they nonetheless enjoy certain gendered advantages at the expense of other female food vendors. This research contributes to a further understanding of the effects of gendered perceptions on the wellbeing of both male and female vendors, and thereby provides stakeholder organisations with knowledge needed to improve the well-being of street food vendors.
\end{abstract}

Keywords: occupational segregation, gender, female-dominated occupations, street food, coping strategies

1. Introduction

1.1 Background of Study

Segregation based on sex is common in the labour market in both developed and developing economies (Cross \& Bagilhole, 2002; Simpson, 2005). This sex-based occupational segregation is embedded in socio-cultural norms that often determine the appropriateness of an occupation for a man or a woman (Schaefer, 2004). Nonetheless, some men and women do overcome occupational segregation by working in occupations that are not traditional to their sex (Cross \& Bagilhole, 2002; Simpson, 2005).

In the broader context of Ghana, street food vending is traditionally perceived as an occupation for women (Nimura \& Eisen, 2010). Nonetheless, the changing economic conditions mean that men negotiate and challenge this traditional perception by engaging in food vending (Overå, 2007). Consequently, an increasing number of men are entering the street food sector as street food vendors. However, usually men vend fried rice and women vend Traditional Foods (TFs) $\left(\mathrm{Fufu}^{1}, \mathrm{Banku}^{2}\right.$ and Kenkey ${ }^{3}$ ) and operate chop bars ${ }^{4}$ (Overå, 2007). This segregation of the sexes within the street food sector in Ghana has received very little research attention. Most of the research in Ghana for instance have focused on the quality of raw materials used by street food vendors (Afele, 2006), the hygiene of the vending environment (King, Awumbila, Canacoo, \& Ofosu-Amaah, 2000; Rheinländer, Olsen, Bakang, Takyi, Konradsen, \& Samuelsen, 2008) and the microbial content of street vended foods (Mensah, Yeboah-Manu, Owusu-Darko, \& Ablordey, 2002). Thus, the focus of research has been predominantly on health and safety without much attention to the socio-cultural aspects of street food vending. Overå (2007) investigated broadly the livelihood and coping strategies of both men and women who cross gender barriers into different informal sector occupations within a patrilineal social setting (Accra) in Ghana.

\footnotetext{
${ }^{1}$ Fufu is prepared by boiling plantain and cassava and pounding in a mortar with a pestle, while turning it over with the hand (Feglo \& Sakyi, 2012: 3).

${ }^{2}$ Banku is fermented maize dough dumplings prepared and served with either soup or stew (Mensah et al. 2002: 547).

${ }^{3}$ Kenkey refers to fermented maize dough dumplings wrapped in cornhusk, boiled, and served hot with pepper sauce and fish

(Mensah et al. 2002: 547).

${ }^{4}$ A chop bar refers to a local eating-place usually serving Banku, Fufu, and Kenkey.
} 
Unlike Overå's study, the present study specifically explores how men negotiate their position as Male Traditional Food Vendors (MTFVs) within a matrilineal social setting (Kumasi) in Ghana. The uniqueness of this study therefore lies in its focus on male advantages, constraints and coping strategies within a traditionally prescribed female occupational field (traditional food vending), in a matrilineal social setting with patriarchal values. With such a focus, this study complements the existing literature on street food research in Ghana and to the emerging and broader literature on Men in Female-Dominated Occupations (MFDOs). It contributes to a further understanding of the effects of gendered perceptions on the well-being of both male and female vendors, and thereby provides stakeholder organisations with knowledge needed to improve the well-being of street food vendors.

\subsection{Theoretical Framework of Study}

Relying on the typology developed by Williams \& Villemez (1993), Simpson (2004) found three main categories of men (seekers, finders, and settlers) according to their mode of entrance into female-dominated occupations. Seekers are those who actively choose female-dominated occupations, while finders are men who come across the female-dominated occupation as they search for a job (Willliams \& Villemez, 1993). Settlers are those who, after failing to achieve job satisfaction in male-dominated occupations, 'settles' for the female-dominated occupation. In explaining what motivates them to move into female-dominated occupations, some MFDOs emphasize job satisfaction and self-fulfilment while others emphasize pay increase and career progression as motivating factors (Simpson, 2005). However, irrespective of their motivations, men often enjoy certain gendered but 'hidden' advantages within female-dominated occupations (Williams, 1992; Evans, 1997; Lupton, 2000; Cross \& Bagilhole, 2002; Simpson, 2004). These advantages help further the career of men, a phenomenon that Williams (1992) terms as the 'glass escalator', an escalator that 'kicks' men up the occupational ladder at the expense of the dominant females (Williams, 1992). Although the glass escalator may not work at all levels of a female dominated occupation (Williams, 1992) and is also affected by race differences (Maume, 1999), it will be interesting to see whether this concept lends analytical power to a study conducted in an informal occupational setting where there are unclear or non-existing social and administrative hierarchies.

Another important concept used to explore the advantages that MFDOs enjoy is Floge \& Merril's (1986) concept of the 'heightened visibility'. This concept argues that the advantages that minority groups might enjoy in organizations result from the fact that as a minority group, their actions are easily noticed or highly visible, creating the impression that they are working harder than others, which in reality may not be so. Sometimes the name and some other personal identification of members of minority groups are known more than that of the dominant group members, making them easy to find within particular organizations (Floge \& Merril, 1986). This concept will help investigate whether MTFVs in Ghana enjoy occupational advantages as a result of their minority status within the street food sector.

Despite the advantages that MFDOs may enjoy, literature has also highlighted socio-cultural occupational challenges. Studies in Great Britain and England for instance, have shown that some MFDOs suffer identity crisis, a challenge to their masculinities, and a questioning of their sexualities (Lupton, 2000; Cross \& Bagilhole, 2002; Simpson, 2005). One study further stressed that MFDOs may suffer 'role strain' because of the need to maintain masculine identities against the feminine demands of the job (Simpson, 2005). One strategy that MFDOs use in coping with these challenges is to redefine their job to fit masculine conceptions (Evans, 1997; Lupton, 2000; Simpson, 2004; Simpson, 2005). For instance, Cross \& Bagilhole (2002) reveal that male carers redefine their work as 'enablers and facilitators', for the needs of others. Another common strategy is for men to change their perception of what it means to be a man (Lupton, 2000). Lupton (2000) reports of MFDOs who argue that masculinity is demonstrated by the ability to work in a female-dominated environment. Thus, perceptions of masculinity are modified to make transition into a female-dominated occupation much easier (Lupton, 2000). These and other strategies allow MFDOs to create 'islands of masculinity' within the female-dominated occupations (Egeland \& Brown 1988 cited in Evans 1997).

The literature reviewed above engages with the formal sector and not much is known about MFDOs in the informal sector or MFDO's in low and middle-income settings. Do men enjoy gendered advantages or constraints in the informal sector in Ghana? What can explain such advantages and constraints when men venture into female dominated occupations in an informal sector? Would men in an informal sector employ similar coping mechanisms as used by men in the formal sector? These questions guided this research.

\section{Research Setting}

The city of Kumasi lies 270km north of Accra, the capital city of Ghana. The 2010 population and housing census revealed that the Kumasi metropolis had a population of 2,035,064 (Ghana Statistical Service, 2012). Kumasi is a major trading and transport hub in Ghana and in the West African sub-region. As a result, a lot of travellers, goods, and services pass through the city to other parts of Ghana, and the West African sub-region on a daily basis (Adarkwa, 2011). Because of the city's inability to attract many direct foreign investments, the growth of the city of Kumasi has mainly been driven by the private and informal sectors (ibid). It is estimated that about $75 \%$ of the city's labour force work within the informal sector (Adarkwa, 2011). Approximately $60 \%$ of those employed within the informal sector are engaged in 
trading, including hawking and street food vending (ibid). As at September 2014, it was estimated that approximately 20,000 street food vendors operated in the Kumasi metropolis (Personal communication with the Metropolitan Environmental Health Director, $5^{\text {th }}$ September 2014). These street food vendors serve as an important source of food for both the people in Kumasi as well as for travellers and traders passing through the city to other parts of the country and the West African sub-region.

In terms of its inhabitants, Kumasi is the home of the Ashantis and capital of the Ashanti region, which has always been an influential region of Ghana (Amoako, 2011). The Ashanti people are one of the most prominent ethnic groups of the Akan speaking groups in Ghana. As an ethnic group, the Ashantis are organised around matrilineal descent systems and this matrilineal descent system serves as a foundation for social organisation (Johnson, 1970). Like many of the Akan speaking groups however, Ashanti men occupy privileged positions, are traditionally respected and revered, and their word has/is perceived to have more authority than that of females (Ankomah, 1996). Even though men continue to be dominant and respected in this matrilineal system, one prominent area of dominance and authority for Ashanti women is in trading and in food preparation and sale. Clark (1994) asserts that street vending not only serves as a valuable source of income for women in Kumasi, but also as a source of social status and prestige. As a result, trading and food vending in general is a 'stereotypically' female occupation among the people of Kumasi.

\section{Research Methods}

The study reported here is part of a larger research that investigated the street food sector in the Kumasi metropolis. Fieldwork was carried out over a period of 23 months, from October 2012 to September 2014 by the first author. The study used the qualitative tools of participant observation and interviews in different forms to gather information from respondents.

\subsection{Data Collection}

In addition to the overall insight gained from the larger study, this paper specifically draws on data from 39 street food vendors (14 MTFVs and 25 female street food vendors), 7 consumers and 17 street food regulators. Because MTFVs are a small and unique sub-set of food vendors within the metropolis, food vendor associations like the Traditional Caterers Association of Ghana (TCAG) served as key informants in identifying three MTFVs. From these initial MTFVs, snowball-sampling techniques were used to identify the remaining 11 MTFVs. Going through the vendor associations ensured that researchers gained the trust of the initially identified MTFVs, whose recommendation in turn facilitated access to and the willingness of other MTFVs to participate in the study. The MTFVs selected as part of this research represent a diversity of age, experience, and mode of operation. Three of the MTFVs operated from within large markets; three operated close to the roadside, one hawked the food, while the remaining operated from within their respective communities. All MTFVs had employed helpers (mostly female), ranging from one to five per MTFV.

As part of the larger research study, twenty-five female vendors vending a variety of foods were selected from areas of high food vendor concentrations. Including these female vendors made it possible for researchers to confirm and or contrast some of the themes that were emerging as the research progressed. For instance as a result of the emerging themes, female food vending stands were observed in terms of organisation, hygiene, and management and then compared with that of MTFV food vending stands. Female food vendors were also interviewed on their perceptions of the emerging phenomenon of MTFVs and its effect on the street food sector. Semi-structured interviews with these street food vendors took place at their vending sites.

The selection of consumers was done by convenient sampling from male food vending stands. The consumers were interviewed about their perceptions and experiences with male and female food vendors in the metropolis. Interviews with the consumers were unstructured and conversational in nature. Purposive sampling techniques were also used to select 17 street food regulators. Interviews with regulators were semi-structured and took place in their offices at arranged times. These interviews focused, among other things, on their experiences with and perceptions of male and female food vendors within the Kumasi metropolis.

Interviews were conducted by the first author and a research assistant, both fluent in the native language of Twi (used when interviewing vendors and consumers), and in the English language (used when interviewing food regulators). In addition to the interviews, the first author and the research assistant visited and observed different street food vendors during the course of the fieldwork, at different times of the day and on different days of the week. Researchers observed the interaction between MTFVs and their customers for instance, as well as the general organisation of MTFVs and other female food vendors. Observational and reflective notes were taken to provide context for the transcripts, to enrich the interview data and to deepen or challenge emerging themes and assumptions from the interviews.

\subsection{Data Management and Analysis}

All interviews were audio recorded and transcribed ad verbatim by the first author and the research assistant. After the transcripts had been read through, it was organised under two broad categories (the socio-cultural advantages men enjoy 
as TFVs; and the socio-cultural constraints men face as TFVs), which were further scrutinised, given descriptive codes and organized into themes. All authors have been actively involved in discussions of the data and the analytical framework. Findings will thus be presented by two sub-themes of 'socio-cultural advantages that men enjoy as TFVs' including 'uniqueness and attraction' and 'gendered perception of neatness and trust', and Socio-cultural constraints and coping strategies'.

\subsection{Ethical Considerations}

The ethical issue of informed consent was overcome by sending a formal request to institutional heads (the metropolitan Environmental Health Director of KMA) outlining the nature of the research, the intention, the methods to be used and the time. All participants in the study including food vendors also gave their consent to participate. At the beginning of each interview, the researcher made respondents aware of their right to withdraw from the interview or refuse to answer a particular question, without fear or favour or without harm to their person, reputation and esteem. The real names of respondents and places of operation have been changed in the presentation of findings in order to preserve the anonymity and confidentiality of respondents. Respondents' gender and years of operation have been maintained.

\section{Findings}

With the exception of one of the MTFVs, a hawker of street foods, the remaining MTFVs were permanent vendors and operated from wooden structures with separate cooking and eating areas. Their working lives involved working up to 15-18 hour days for six days a week. All but one of the MTFVs were married with children. Nonetheless, only one of the married MTFVs worked with their wives as food vendors. The wives of the other MTFVs were engaged in other informal sector occupations. All but two of the MTFVs were Ashantis. The two other MTFVs were migrants from the Central and Northern regions of Ghana respectively. These are the socio-demographic characteristics of the MTFVs included in this study.

All but one of the MTFVs included in this research indicated that vending TFs was not an ideal occupational choice but rather an occupation that they came into as a result of either a tragedy in life or because it was the only available option while they were seeking for a job. The MTFVs mentioned occupations like being in the Army, Furniture making, and Tailoring as their intended or ideal occupations. Thus, most of the MTFVs included in this research can be classified as 'finders', those for whom vending was either a second option or simply the available option. For one of the MTFVs however, food vending was his dream occupation and he actively worked to achieve this dream. This particular MTFV can be classified as a seeker, those men who dream of and vigorously seek to engage in a predominantly female occupation (Simpson, 2004). Irrespective of their mode of entry however, these men enjoy certain gendered advantages and constraints when they become street food vendors. These advantages and constraints are discussed in the following sections.

\subsection{Uniqueness and Attraction of Male Traditional Food Vendors}

When a group of people form the extreme minority in an occupation, they become highly visible, and their actions easily noticed (Floge \& Merril, 1986). Similarly, being an MTFV serves as a form of attraction, drawing consumers to a particular food stand. One female consumer explains:

'Well, for that one it is not normal. We know it is women who cook, and so if you see a man selling, that alone attracts you to go and try. We know that the kitchen is not a place for men, so you see a man selling Kenkey and, because of that attraction, you decide to go and try this man's food. If it is good, then you begin to prefer the man's food to that of other female food vendors' (female consumer).

This 'abnormality' of the MTFV then serves as a force of attraction, and sometimes even when there are other women in the vicinity vending similar foods, the man will usually get more customers not because of the better taste of his food per se, but mainly as a result of the uniqueness or deviant nature of his activity. The example below by a female consumer helps to illustrate this point:

'For instance, where I am coming from, one-man sells Kenkey and he is in a line with many women who are also vendors of Kenkey. He is the only man but when you see the crowd that is always at his stand, and you wonder what kind of Kenkey he is selling. But when you taste the foods, they all taste the same, it's just this issue of him being a man and selling food, that attracts people' (female consumer).

Clearly, being a man and vending TF is a huge advantage in terms of customer attraction. Sometimes, a fascination with the activity of these men attracts consumers. Kojo explains that for some of his female consumers, it is 'a beautiful sight for them to behold! Many men come here but many women do also, and for the women some do come here, watch me work and they laugh. When I ask them why, they say they are fascinated' (Kojo, a male chop bar operator for 23 years). Another important point is that consumers do not only buy food from MTFVs but they also tell others about them. When a person comes across one MTFV in their community, they inform their friends and relatives. Afful explains that 
'since I am a man and doing a woman's job, that is what attracts the customers. Somebody may come and buy food, when they go they will say to their friends, I went and bought food at such and such place and it was men who were vending' (Afful, a male chop bar operator for 4yrs). To the extent that wherever a man vends TF, they are well known within that particular community. The observation of this research confirms this fact. The MTFVs are affectionately referred to as 'barima nkwan', which literally means 'a man's soup' in their respective communities. Hence, consumers advertise these men to their friends and relatives and this heightened visibility, as has been demonstrated, serves as an important economic advantage for MTFVs.

\subsection{Gendered Perceptions of Neatness and Trust}

Within the Kumasi metropolis, some traditional and religious beliefs have effect on the behaviour of consumers and in turn translate into gender based economic advantages for MTFVs. These advantages are discussed under two main themes: the gendered perceptions of neatness; and the uniqueness of MTFVs.

\subsubsection{Neatness}

The interviews revealed that there exists a strong gendered perception of neatness, with MTFVs regarded as more hygienic compared to female vendors. As a result, some consumers prefer to buy food from MTFVs because: 'MTFVs are neat, when you go to their places, these places are neat. But excuse me to say that when you visit some of the women at their places of business, it is not nice' (Kofi, a male chop bar operator for 13yrs).

The traditional association of women with child care also serves as another advantage for MTFVs. In discussing why she prefers purchasing food from MTFVs, this female consumer explains: 'it is because the MTFVs are neat ... they will not go and wipe the buttocks of their baby and use it to come and sell food for you.' The concern here is that a female vendor with a child may come and sell without properly washing her hands. The fact that this sentiment is expressed by another female is in itself a powerful indication of the extent of the disadvantage that domestic responsibilities pose for the economic well-being of women and the economic advantages that men enjoy as a result. In addition to the above, in terms of personal appearance, men are considered to be 'far far better than the women' (female food regulator), since the women 'usually have a lot of problems including bad dressing, unkempt hair, and usually appear dirty' (male food regulator). Based on his experience of regulating food vendors, this male food regulator argues that: 'when you go to the food premises where men are selling, they are smart in serving and they serve you quickly. They have better customer relations and I have observed that their eating-places are neat and personally, they are neat'. These gendered perceptions of neatness encourage some consumers to prefer purchasing food from MTFVs rather than from their female colleagues. By increasing the consumer base of MTFVs, these gendered perceptions enhance better profit margins for MTFVs than for female vendors. Thus, these gendered perceptions could be viewed as push factors, a form of a glass escalator, enhancing the occupation and economic well-being of MTFVs at the expense of female food vendors.

The fact that men do not menstruate also serve as a major advantage for MTFVs. Among some consumers, the uncertainty regarding whether or not a female vendor is menstruating is enough reason for them to patronise the foods of MTFVs. The statements of Ayisi and Kofi below illustrate the strong feelings that exist about menstruation:

'Even the Bible indicates that ideally even if a woman menstruates, she should not even cook for the husband or even eat with the husband. You can study and find out, the women food vendors are always selling throughout the 30 days, including during their menstrual period. However, when you menstruate it is filth! Why should you menstruate, come and cook for people?' (Ayisi, male chop bar operator for 6yrs).

Kofi, a male chop bar operator for 13yrs further argues that 'some women, huh! She will do "it" (have her period) and come and sit down with 'it' and sell food. Even if the menstrual pad is 'there', she will come and sit there with it and sell food. But a man will not have his period; he is always clean'. These religiously founded ideas about menstruation add to the general perception of 'women as unclean' that female vendors are faced with compared to MTFVs. Menstruation, which is an aspect of womanhood is therefore used to enhance the distinction between men and women and to increase the 'perceptions of dirtiness of women'. The MTFVs are aware of the advantages that these believes produces and take full advantage of them. Takyi explains that:

'For a man, at all times there is no filth/dirt attached to you. You see some women will menstruate and be cooking and selling with it. However, for a man, still strong, we are always available and we are always clean. Therefore, if it happens that a man is really determined to vend food and you are a good cook, they will definitely patronise your food more than the women will. Therefore, men have such an advantage'(Takyi, a male chop bar operator for 12yrs).

\subsubsection{Trust}

Interestingly, observations revealed that despite the perceptions of dirt and uncleanliness attached to female vendors, all the MTFVs employed women as helpers to do the cooking. What the men did mainly was to supervise the preparation 
of the food and to have customer contact. Kojo explains in relation to his female employees that, 'I may sometimes stand over them and direct them while they work...I will then come and stand by it and sell it myself'. Thus, it could be argued that these MTFVs occupy managerial positions, similar to other MFDOs. Furthermore, observations of both MTFVs and female headed TF vending stands revealed that there were no significant differences in terms of cleanliness, order and hygiene. Some female vending sites were clean just as some male vending sites were unclean. Nonetheless, the mere presence of 'a man' appeared to assure some members of the public of order and hygiene. In a conversation with one street food regulator, he insisted that 'when there are men involved, you will see that there is discipline...the men are disciplined'. This demonstrates that in addition to neatness, perceptions of trustworthiness and discipline of men serves as important advantages for MTFVs. As a result, some female TFVs become 'jealous...because they are aware that you are a man and that people buy your food a lot' (Kojo).

Together, the gendered perceptions regarding cleanliness and menstruation, and the emerging issues of trust serve as important platforms for male advantage over females; it serves as an escalator that pushes men higher up by increasing their consumer base than that of women. Men are subsequently perceived as a 'safer, cleaner and trustworthy' source of food for a number of people.

\subsection{Vending Traditional Food: Socio-Cultural Constraints and Coping Strategies}

Contrasting the above positive discrimination of men, men performing a role which society considers as 'female' are also at risk of suffering social sanctions in various forms (Lupton, 2000). Drawing on interview responses, this study found that in addition to gendered advantages, all male vendors also experienced sanctions in the form of social ridicule. Kojo's illustration below demonstrates how strong social reactions can be when there is a perceived breach of the cultural norms regarding gender appropriate occupations: 'since I started this job, people complained, why is a man selling Kenkey? Why don't you go and find a better job to do? Some people may see you and say that... why should you do a woman's job?' (Kojo). It appears that finding a 'better' job to do and not doing 'a woman's' job then is what is expected of a man. Interestingly, despite consumers and the public's trust in MTFVs' organisational and managerial capabilities in preparing food hygienically, MTFVs are still expected to find a better job. This applies in an even stronger sense to mobile MTFVs who carry the foods around to sell; the social reaction goes beyond ridicule to that of questioning that man's masculinity. Ayisi explains that: 'each day after cooking, I carried the food on my head...and each time I carried, they called me 'obaa barima' (translates into: man-woman)' (Ayisi). In Twi (language of the Ashantis), 'obaa barima' is derogatory for those men who demonstrate behaviour socially associated with females. Once again, it is difficult to reconcile the fact that MTFVs are considered as unique and attractive, clean and trustworthy to some consumers, yet in other instances, certain consumers ridicule MTFVs. Some consumers, in view of the prevailing economic situation in Ghana, understood why some men would vend traditional foods. Nevertheless, these consumers still insisted that food vending was not an appropriate occupation for a man it is because of the difficult economy...that is why men are doing women's work. However, it reduces their masculinity. Men are not even supposed to sell rice. Of course, God did not assign the sale of rice to women but it is disgraceful if they sell it. However, it is because of the difficult economic situation' (female vendor). Thus, from the preceding comments, these consumers are attempting to understand the emerging urban phenomenon of MTFVs in times of change and economic difficulties and within a complex setting where beliefs and religious ideologies persist.

Since masculinity confers advantages on men, men usually devise ways of protecting their masculinity whenever it comes under threat (Lupton 2000). This research found that MTFVs adopted two main strategies, either to focus on the advantages that the job provides or try to justify the work they do. With the first strategy, MTFVs indicated that they coped by arguing that they focused on what was 'important', that is, the profits they gained from the job. Kofi for instance indicated that, the profit he got and the subsequent ability he had to feed his children was enough justification for the work he did. He explains that 'what is important is what you will do to get money...for chop bar business, if you do it and do it well, it is good because even if you don't get a lot of money, your children will be fed' (Kofi, male chop bar operator for 13yrs). Similarly, Abu emphasized the assurance of a better future in addition to the ability to take care of his children 'well whether it does reduce my masculinity or not I do not care. What is important is how I can take care of my future... how I will be able to take care of my children, which is what is important' (Abu, a male chop bar operator for 6yrs).

In the second strategy, the emphasis was on the job itself and the legality of the activity. MTFVs indicated that they responded to the social ridicule by asking those who taunt them whether they would prefer that they were engaged in an illegal activity. Asamoah, a male mobile food vendor for $12 \mathrm{yrs}$ explains, 'Oh, I tell them that if they had met me being beaten up as a thief what would they have said, and so if I am doing this why are they complaining'.

By these strategies, MTFVs respond to the socio-cultural constraints by adopting a different attitude in order to continue enjoying the gendered advantages that comes with working within a female dominated occupation. 


\section{Discussion of Findings}

This study investigated the advantages men enjoy as TFVs in Kumasi, the socio-cultural constraints that MTFVs face and their strategies for handling the socio-cultural constraints. It's been revealed that some local beliefs and values work in many ways to give MTFVs advantages even within a female-dominated occupational sector. In both formal and informal employment sectors, such advantages tend to enhance the careers of men (Williams, 1992), in this case, by increasing the consumer base for MTFVs. This finding is consistent with the reviewed literature about MFDOs where men are perceived by management to possess better managerial qualities and so are 'kicked upstairs' on a glass escalator with increased pay and prestige (Williams, 1992; Evans, 1997; Lupton, 2000; Simpson, 2004). The male vendors in Ghana similarly take these gender-related privileges with them into a female-dominated occupation of food vending-even within an informal sector lacking any clear managerial and hierarchical structures and within a traditionally matrilineal society like Kumasi. Within the study context of patriarchal values (Ampofo, 2001), like in other patriarchal societies, men are often considered to possess the qualities for effective management, and male attributes are often used to describe who a good manager is (Heilman, 2001; Eagly \& Carli, 2008). This is more so when culturally and socially prescribed male attributes in Ghana include authority, power, and good leadership while those for women include submissiveness, obedience, conformity and empathy (Ampofo, 2001). This may explain why, even though some MTFVs are not directly involved in the preparation of foods, consumers and the public trust that the mere presence of a man assures order in terms of hygiene. Here, this study re-emphasises the prominence of gendered patriarchal values over matrilineal ideals, the assertion that gendered attitudes emerging out of patriarchy often transcend lineage type (Ampofo, 2001). Even though some women, including queen mothers, traders and market women in matrilineal societies occupy prominent positions and enjoy economic and political advantages compared to women in other African settings (Boaten, 1992; Gneezy et al., 2009), findings from this research further questions the extent of female economic advantages and competitiveness within urban and modernizing matrilineal social settings such as Kumasi.

As a result of cultural expectations, choosing to vend TFs mean a compromise of what it means to be a 'man' in Kumasi since being a man means getting out of the house and engaging in economic activities that demonstrate 'virility and wisdom' (Dako-Gyeke \& Owusu, 2013). Such contradictions demonstrate some of the contradictions that emerge between locally held norms and values and newer and modern ideas of gender and occupations in urban settings like Kumasi (Barker \& Ricardo, 2005). The two main coping strategies identified in this study are similar to strategies identified in other research studies on MFDOs (Lupton, 2000; Cross \& Bagilhole, 2002). By emphasising the financial rewards, MTFVs were emphasising aspects of their jobs that underlie their qualities as 'men' since, having a source of income and gaining financial independence is one of the ways of achieving and maintaining one's manhood in Africa (Barker \& Ricardo, 2005). These strategies help to support and maintain masculine identities and masculine advantages that otherwise are threatened by being associated with feminine characteristics (Simpson, 2004). The fact that these men are negotiating gender roles lends more evidence to the argument that gendered division of labour has never been historically fixed (Kornblum, 2003). According to Kornblum (2003), gender roles have historically been adapted to suit new and emerging conditions, from hunting and gathering societies, through horticultural and agrarian societies to industrial and post industrial societies. In modern urban societies, Overå (2007) has suggested that the migrant status of informally employed men and the anonymity they enjoy in urban areas as a result, allow men to negotiate and play with gender roles, which otherwise would have come under close critique from family and friends. Thus, the urban area, characterized by impersonal relationships (Kornblum, 2003) and emphasis on economic and financial well-being, presents MTFVs with a unique arena to negotiate gender roles and to gain advantages in a female economic sphere like traditional food vending.

The data revealed some contradictions at play within the socio-cultural setting of the study. Even though menstruation is considered as a sign of fertility, power, and womanhood among the Akans of Ghana (Agyekum, 2002), this research has revealed contrasting and negative perceptions of menstruation which serves as important forms of advantages for MTFVs within the study setting. While the argument has been made that such negative perceptions are waning because of modernization, not all aspects of cultural beliefs are modified through social change (Agyekum, 2002).

The preceding discussions also reveal that, while MTFVs enjoy the advantages of the glass escalator, they have to learn how to negotiate the gendered challenges that come with working in a female-dominated occupation in order to continue enjoying the advantages of the glass escalator. Based on this, we argue that the glass escalator is not a given for these MTFVs, as it is sometimes portrayed to be in literature (Maume, 1999; Budig, 2002; Wingfield, 2009). On the contrary, the escalator, like its literal counterpart is only effective when its doors are worked at or opened and the appropriate buttons pressed.

\section{Conclusion}

The informal street food sector in urban cities of Africa is rapidly growing and men are now an active part of this 
traditionally female-dominated sector. This research has confirmed that Male Traditional Food Vendors enjoy advantages emerging out of the socio-cultural context, advantages which present new challenges for women in the sector. These men are also battling different socio-cultural constraints compared to women in their jobs (including social ridicule from members of the public), and adopt coping strategies that are similar to other men in formal sector female-dominated occupations. This research makes important contribution towards the emerging understanding of gendered perspectives of men in female-dominated occupations in the under-studied context of an informal occupational sector in a Sub-Saharan African setting. As such, this study complements findings from other gender based occupational research studies which has largely focused on formal sector occupations in Western and urban settings. This research also furthers an understanding of how the concept of 'glass escalator' works within an informal occupational sector by demonstrating that in the informal street food sector, the glass escalator works in the form of increased consumer base for men vending Traditional Foods. This study also contributes to a deeper understanding of how local and traditional beliefs of cleanliness, trustworthiness, and filth are gendered, and influence the economic well-being of male as well as female vendors. It is appropriate also to conclude that given the economic advantages enjoyed by men, an increasing number of men may continue to enter the street food sector as street food vendors in Africa, especially in the face of changing economic conditions, in modernizing urban African settings. Consequently, this research provides an important knowledge base for stakeholders working to improve the conditions of the numerous men and women engaged in the informal street food sector.

\section{Acknowledgements}

This research received funding from the Danish International Development Agency (DANIDA), through the Ghana Street Foods Project in Kumasi.

\section{References}

Adarkwa, K. K. (2011). The role of Kumasi in national development-Kumasi as a central place. In K. K. Adarkwa (Ed.), Future of the tree: towards growth and development in Kumasi, 14-34. Kumasi: University Printing Press.

Afele, M. (2006). Street food boom in Ghana spurs calls for better hygiene. Bulletin of the World Health Organisation, 84(10)(June), 772-773.

Agyekum, K. (2002). Menstruation as a verbal taboo among the Akan of Ghana. Journal of Anthropological Research, 58(3), 367-387.

Amoako, C. (2011). Historical Development, Population growth and present structure of Kumasi. In K. K. Adarkwa (Ed.), Future of the tree: towards growth and development in Kumasi , Kumasi: University Printing Press, 35-54.

Ampofo, A. A. (2001). “When Men Speak Women Listen ": Gender Socialisation and Young Adolescents ' Attitudes to Sexual and Reproductive Issues. African Journal of Reproductive Health, 5(3), 196-212.

Ankomah, A. (1996). Premarital relationships and livelihoods in Ghana. Gender and Development, 4(3), 39-47. http://dx.doi.org/10.1080/741922169

Barker, G., \& Ricardo, C. (2005). Young Men and the Construction of Masculinity in Sub-Saharan Africa : Implications for HIV / AIDS , Conflict, and Violence . Washington. D.C.

http://dx.doi.org/http://www-wds.worldbank.org/servlet/WDSContentServer/WDSP/IB/2005/06/23/000012009_20 050623134235/Rendered/PDF/327120rev0PAPER0AFR0young0men0WP26.pdf

Boaten, N. A. (1992). The changing role of Queenmothers in the Akan Polity. Research Review, 8(1\&2), 90-100.

Budig, M. J. (2002). Male Advantage and the Gender Composition of Jobs : Who Rides the Glass Escalator? Social Problems, 49(2), 258-277.

Clark, G. (1994). Onions are my husband: survival and accumulation by West African market women. Chicago: University of Chicago Press.

Cross, S., \& Bagilhole, B. (2002). Men, Masculinity and Non-Traditional Occupations. Gender, Work and Organization, 9(2), 204-226.

Dako-Gyeke, M., \& Owusu, P. (2013). A Qualitative Study Exploring Factors Contributing to Gender Inequality in Rural Ghana. Mediterranean Journal of Social Sciences, 4(January), 481-490. http://dx.doi.org/10.5901/mjss.2013.v4n1p481

Eagly, A. H., \& Carli, L. L. (2008). Women and the Labyrinth of Leadership. Harvard Business Review, Feature Ar, 19.

Evans, J. (1997). Men in nursing : issues of gender segregation and hidden advantage. Journal of Advanced Nursing, 26, 226-231. 
Floge, L., \& Merril, D. M. (1986). Tokenism Reconsidered : Male Nurses and Female Physicians in a Hospital Setting. Social Forces, 64(4), 925-947.

Ghana Statistical Service. (2012). 2010 population and housing census: summary report of final results. Accra.

Gneezy, U., Leonard, K. L., \& List, J. A. (2009). Gender differences in competition: evidence from a matrilineal and a patriarchal society b. Econometrica, 77(5), 1637-1664. http://dx.doi.org/10.3982/ECTA6690

Heilman, M. E. (2001). Description and Prescription: How Gender Stereotypes Prevent Women's Ascent Up the Organizational Ladder. Journal of Social Issues, 57(4), 657-674. http://dx.doi.org/10.1111/0022-4537.00234

Johnson, C. E. (1970). Art and culture among the Ashanti of Ghana. Arkansas Academy of Science Proceedings, XXIV, $18-23$.

King, L. K., Awumbila, B., Canacoo, E. A., \& Ofosu-amaah, S. (2000). An assessment of the safety of street foods in the Ga district, of Ghana ; implications for the spread of zoonoses. Acta Tropica, 76, 39-43.

Kornblum, W. (2003). Sociology in a changing world (6th ed.). Belmont: Thomson Learning Inc.

Lupton, B. (2000). Maintaining Masculinity: Men who do "Women"s Work'. British Journal of Management, 11(s1), 33-48. http://dx.doi.org/10.1111/1467-8551.11.s1.4

Maume, D. J. (1999). Glass Ceilings and Glass Escalators: Occupational Segregation and Race and Sex Differences in Managerial Promotions. Work and Occupations, 26(4), 483-509. http://dx.doi.org/10.1177/0730888499026004005

Mensah, P., Yeboah-manu, D., Owusu-darko, K., \& Ablordey, A. (2002). Street foods in Accra, Ghana: how safe are they? Bulletin of the World Health Organisation, 80(7), 546-554.

Nimura, A. and Eisen, S. (2010). Gender needs assessment for Kumasi, Ghana , (No. No 15,). New York. Retrieved from Viewed 27th October 2013 at: http://mci.ei.columbia.edu/files/2012/12/Kumasi-Gender-Needs-Assessment.pdf

Overå, R. (2007). When men do women's work: structural adjustment, unemployment and changing gender relations in the informal economy of Accra, Ghana. The Journal of Modern African Studies, 45(04), 539-563. http://dx.doi.org/10.1017/S0022278X0700287X

Rheinländer, T. (2006). Street food quality, a matter of neatness and trust: a qualitative study of local practices and perceptions of food quality, food hygiene and food safety in urban Kumasi, Ghana. University of Copenhagen, Denmark.

Rheinländer, T., Olsen, M., Bakang, J. A., Takyi, H., Konradsen, F., \& Samuelsen, H. (2008). Keeping up appearances : perceptions of street food safety in urban Kumasi, Ghana. Journal of Urban Health: Bulletin of the New York Academy of Medicine, 85(6), 952-964. http://dx.doi.org/10.1007/s11524-008-9318-3

Schaefer, R. T. (2004). Sociology: a brief introduction (fifth edit.). New York: McGraw-Hill.

Simpson, R. (2004). Masculinity at Work: The Experiences of Men in Female Dominated Occupations. Work Employment and Society, 18(2), 1-35.

Simpson, R. (2005). Men in Non-Traditional Occupations : Career Entry, Career Orientation and Experience of Role Strain. Gender, Work and Organization, 12(4), 363-380.

Williams, L. (1992). The Glass Escalator: Hidden Advantages for Men in the "Female " Professions. Social Problems, 39(3), 253-267.

Wingfield, A. H. (2009). Racializing the Glass Escalator: Reconsidering Men's Experiences with Women's Work. Gender \& Society, 23(1), 5-26. http://dx.doi.org/10.1177/0891243208323054

\section{(cc) EY}

This work is licensed under a Creative Commons Attribution 3.0 License. 